\title{
sciendo
}

\author{
Current Issues in Pharmacy and Medical Sciences \\ Formerly ANNALES UNIVERSITATIS MARIAE CURIE-SKIODOWSKA, SECTIO DDD, PHARMACIA
}

journal homepage: http://www.curipms.umlub.pl/

\section{An educational review on Probiotics}

\author{
Karur V. Uma ${ }^{1}$, Gunasekaran Sutheeswaran ${ }^{1}$, J. Vineth Martin ${ }^{1}$, \\ Medha Gujadhur ${ }^{2}$, Khayati MoudgiL ${ }^{2 *} \bullet$ \\ ${ }^{1}$ Department of Pharmacy Practice, JSS College of Pharmacy, JSS Academy of Higher Education \& Research, Ooty, Nilgiris, Tamil Nadu, \\ India \\ ${ }^{2}$ Faculty of Health Sciences, School of Pharmacy, JSS Academy of Higher Education \& Research, Mauritius
}

\begin{tabular}{ll}
\hline ARTICLE INFO & ABSTRACT \\
\cline { 1 - 2 } $\begin{array}{l}\text { Received 12 April 2021 } \\
\text { Accepted 15 May 2021 }\end{array}$ & $\begin{array}{l}\text { Probiotics are live microorganisms that appear to provide health benefits when swallowed } \\
\text { or introduced to the body. They are present in dairy and other fermented foods, as well } \\
\text { Keywords: }\end{array}$ \\
$\begin{array}{l}\text { Probiotics, } \\
\text { foods, }\end{array}$ & $\begin{array}{l}\text { other microorganisms are harmful "germs", many are beneficial. Certain bacteria aid in } \\
\text { microorganisms, } \\
\text { tiseases, }\end{array}$ \\
the digestion of food, destroy disease-causing cells and absorb vitamins. Some of the \\
microorganisms found in probiotic products are similar to or identical to those found \\
naturally in our bodies. This article provides sufficient data to support the use of probiotics \\
in a variety of uncommon clinical diseases, including skin disorders, Parkinson's disease, \\
psychiatric disorders, liver transplantation, diabetic foot and periodontal care.
\end{tabular}

\section{INTRODUCTION}

This article presents significant evidence for the benefit of probiotics in uncommon health issues such as skin illnesses, Parkinson's disease, psychiatric issues, liver transplantation, diabetic foot and periodontal treatment. Probiotics have shown promising benefits in reducing skin sensitivity, protecting against UV radiation, immunomodulation, and in preventing and treating dermatitis. Additionally, they contribute to the maintenance of the skin's $\mathrm{pH}$ by inhibiting pathogenic microorganisms selectively. Probiotics have been shown to reduce inflammatory responses and enhance anti-inflammatory responses in Parkinson's disease. Additionally, they demonstrate antioxidant action and enhanced gut integrity. Because the gut microbiota is involved in the creation of key neurotransmitters necessary for mood, cognition, and behavior, supplementing with probiotics aids in the recovery of mental health in individuals suffering from psychiatric disorders such as schizophrenia, depression and others. Patients administered probiotics who have undergone liver transplantation, have experienced significant decreases in post-operative infections, ICU stay and hospitalization, non-bacterial infectious sequelae, bilirubin concentrations and AST/ALT levels. Although there are insufficient trials to demonstrate the efficacy of probiotics in treating diabetic foot infection, this article discusses treatment options for

\footnotetext{
* Corresponding author

e-mail: khayatimoudgil@jssuni.edu.in
}

diabetic foot infection. Periodontal disease has also been historically difficult to treat due to antibiotic resistance, hence, this paper discusses the treatment of a specific bacterium that causes periodontal disease. Alternative therapies have proven critical in the fight against antibiotic resistance. Probiotics are one such treatment modality.

\section{Probiotics in Indian scenario}

In India, the prevalence of non-communicable diseases and lifestyle disorders such as type 2 diabetes mellitus, fatty liver disease and coronary artery disease has risen alarmingly, paving the way for alternative preventive therapies such as probiotics [1]. Probiotics, it is believed, have a larger application in the prevention and management of a variety of common health problems [2-4]. India holds less than $1 \%$ of the worldwide probiotic market, with Amul, Mother Dairy, Yakult Danone and Nestle making significant contributions. Probiotic research and probiotic foods are gaining traction as a result of growing consumer awareness [5]. Probiotic research has long been regarded as a highly specialized field of study on a global scale. In India, major pharmaceutical companies are attempting to develop novel probiotic products and supplements [6]. The Indian Council of Medical Research (ICMR)/Department of Biotechnology (DBT) has taken the lead in formulating guidelines for the use of probiotics in food, their safety and efficacy assessment, their health claims and their labeling [7]. 


\section{Probiotics in skin disorders}

Probiotics have proven effectiveness against a variety of infections by competing for survival resources and generating antimicrobials that aid in wound healing in individuals with multidrug-resistant bacteria infected skin lesions [8]. Numerous studies have demonstrated that oral treatment of probiotics in conjunction with antibiotics enhances wound healing prior to and following surgery [9]. Probiotics have a variety of beneficial effects on the skin, including reducing irritation, acting as a screen against UV radiation, promoting immune system regeneration and preventing atopic dermatitis [10]. Additional information is presented in (Figure 1).

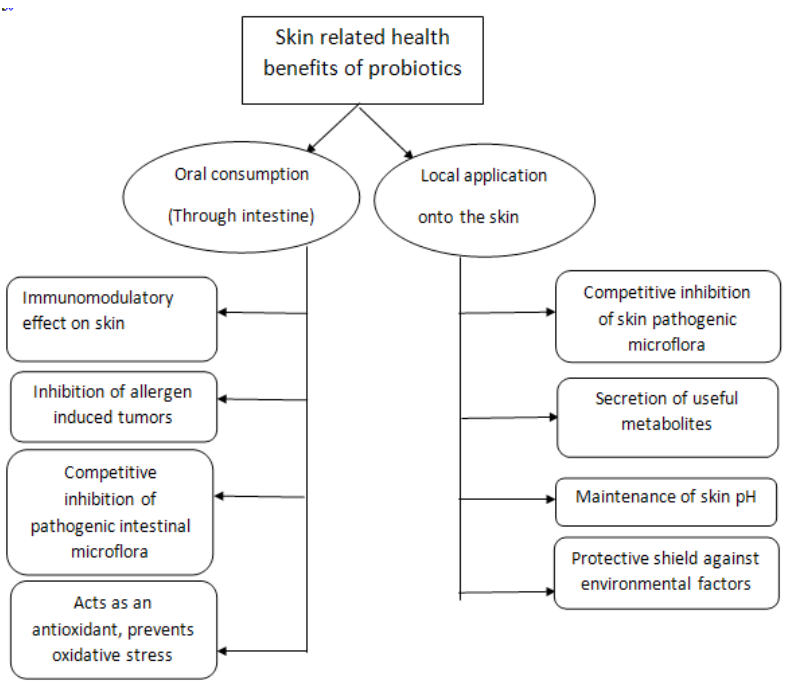

Figure 1. Mechanism of probiotics in skin disorders

\section{Probiotics and Parkinson's disease [11]}

Research in rat models and human subjects have established a possible link between changed gut microbiome and the development of Parkinson's disease. Such work provides overviews of how changed gut microbiota may contribute to the development of Parkinson's disease. Induced Parkinson's disease mice have a higher ratio of Enterobacteriaceae, which is associated with postural instability and gait [12], and lower counts of Prevotellaceae, which are important for the production of the folate and thiamine that are required for intestinal homeostasis.

\section{Benefits [13]}

In a study of 80 Italian patients (40 Parkinson disease +40 controls), $20 \mathrm{ml}$ of blood was drawn and peripheral blood mononuclear cells (PBMC) were isolated using normal procedures. These cells were co-cultured with bacterial probiotic strains belonging to the genus Lactobacillus and Bifidobacterium. Inflammatory (Interleukin-6,17A and TNF- $\alpha$ ) and anti-inflammatory cytokines (IL-4, 10) as well as Reactive Oxygen Species (ROS) were investigated. Certain tests were undertaken, including the effects on intestinal membrane integrity and pathogenicity inhibition, and encoding of the gene tyrosine decarboxylase. The research showed the efficacy of Lactobacillus Plantarum (LP01) and Lactobacillus rhamnosus (LR06) against pathogenic bacteria like Escherichia coli and Klebsiella pneumonia inhibition. In male and female Parkinson disease patients treated with Lactobacillus rhamnosus (LR06) and Bifidobacterium animalis subsp, ROS development was also found to be lower, as for Lactis (BS01).

\section{Probiotics and psychiatric disorders [14]}

Good microbes play a key role in controlling amino acids that serve as building blocks for multiple neurotransmitters such as GABA, glutamate, norepinephrine, serotonin, melatonin and dopamine. Changes in mood, cognition, and actions may be the crippling result of gut microbial disruption.

\section{Probiotics and liver transplantation [15]}

Probiotic bacteria have immunological advantages, as well as non-immunological effects that are as follows:

1. Immunologically, local macrophages have been shown to increase the antigen pin in the body, increase local and systemic development of secretory immunoglobulin A (IgA), which prevents bacterial adhesion to mucosal epithelial cells, and alters the release of cytokines in response to inflammatory stimuli.

2. Probiotics can also establish an unfavorable environment for pathogens through multiple mechanisms that ultimately reduce secondary-infection downstream complications.

3. Non-immunological benefits include detoxification of xenobiotics, biosynthesis of vitamin $\mathrm{K}$ and improvement of peristalsis of the intestines. The following clinical trials were performed using robust methods including randomization, blinding, and placebo control, supporting the use of probiotics as a prevention technique for infections.

Study 1: 95 patients on liver transplantation received a retrospective, randomized research performed in Germany. They were classified into three groups as follows: the first group was treated with enteral nutritional antibiotics and antifungals, but not probiotics $(\mathrm{n}=32)$; the second group was treated with Lactobacillus plantarum 299, along with oat fiber supplementation; and the third group was treated with heat-inactivated Lactobacillus, along with oat fiber. All patients were treated with different immunosuppressive drugs, calcineurin inhibitor and prednisolone, and a total of 60 patients received additional treatment steps, including IL-2 inhibitors, sirolimus and Mofetil Mycophenolate. Intra-abdominal infections were mainly due to enterococcus and other enteric bacteria.

Study 2: 66 patients following liver transplantation were treated with synbiotics. All patients were treated with lowfibre enteral nutrition, prophylactic antibiotics and immunosuppressants, including prednisolone, calcineurin inhibitor, IL-2 inhibitor, and H2 receptor antagonist antihistamines. The isolated bacteria have been identified as having enteric roots.

Study 3: Patients were diagnosed with dual or triple immunosuppressant treatment, which involves medications of the following class: corticosteroid (prednisolone), calcineurin inhibitor, Mycophenolate Mofetil, in a study performed in around 50 adults undergoing liver transplantation. 
Patients with impaired renal function were given an IL-2 inhibitor. Prior to surgery, incompatible recipients of the blood group were provided with Rituximab. As per hospital practice, all patients obtained perioperative prophylaxis through surgery.

Study 4: 67 recipients of adult hepatic transplantation were tested for post-operative bacterial infection. Patients were tested for signs of infection, including fever $>38^{\circ} \mathrm{C}$, $\mathrm{C}$ reactive protein elevation and other clinical symptoms of infection. Bacterial culture was performed and the isolated bacteria mainly detected were enterococci, Escherichia coli and Enterobacter spp.

Study 5: 55 recipients of liver transplants were recruited and a double-blind placebo-controlled study was conducted. The patients were tested for mortality and postoperative infection. The study's secondary objectives included measuring aspartate, AST, ALT, bilirubin, INR after 5 days of surgery, as well as wait-list mortality, MELD (Mayo End-stage Liver Disease) score, changes in child-TurcottePugh and rate of pretransplantation infections. Enterococcus faecium was the most commonly isolated pathogen and was preceded by Klebsiella pneumonia.

\section{Probiotics and diabetic foot [16]}

Damage to the skin may occur due to underlying health conditions, such as diabetes. This in effect causes extra cost with regard to patient's health care and impairs the individual's quality of life. Biofilm forming bacteria such as Staphylococcus aureus, Pseudomonas aeruginosa, Enterococcus faecalis, Acinetobacter baumannii, Escherichia coli, Klebsiella pneumoniae, Enterobacter spp., Peptostreptococcus spp. are common. In treatments, probiotics serve as an important alternatives to antibiotics for the following reasons:

- stimulation of the production of immune cells;

- competitor development;

- function as a signaling receptor in the skin's epidermis and dermis layers against pathogens by activating betadefensins that provide additional immunity to the skin.

Like other cases, clinical trials specifying the benefits of probiotics in diabetic foot infection are not available, but as a point of interest, the probiotics used against the aforementioned pathogens in various clinical settings can be reasonably considered to provide a rough overview of the treatment of diabetic foot-related infections. More description is given below in (Table. 1).

\section{Probiotics in periodontal disease [17]}

Periodontal disease is divided into two groups, namely gingivitis and periodontitis. The former induces gingiva inflammation, while the latter affects all the supporting tissue that surrounds the teeth. Popular pathogenic species responsible for this condition include: Porphyromonas gingivalis, Treponema denticola, Tannerella forsythia, and Aggregatibacter actinomycetemcomitans. Probiotics work against these species through direct pathogen inhibition and/or activation of pathways for host defense. Probiotics function by means is explained in (Table 2), with benefits listed.

Table 1. Probiotics whose use could be extended to diabetic foot infection management

\begin{tabular}{|c|c|c|c|}
\hline Pathogen & Probiotic Strain & Treatment Duration & Clinical Condition \\
\hline \multirow{4}{*}{ Staphylococcus aureus } & $\begin{array}{c}\text { Lactobacillus casei Shirota } \\
\text { Bifidobacterium } \\
\text { Breve Yakult/2*108 cfu } \\
\end{array}$ & Oral for 14 days after surgery & Biliary cancer surgery \\
\hline & \begin{tabular}{|c|} 
Pediococcus pentosaceus LMG P-20608, \\
Leuconostoc mesenteroides LMG P-20607, \\
Lactobacillus paracasei subsp. Paracasei LMG p-17806, \\
L. plantarum LMG P-20606 $1010 \mathrm{cfu}$ \\
\end{tabular} & $\begin{array}{l}\text { Oral from the day of surgery up to } 2 \\
\text { weeks }\end{array}$ & Liver Transplantation Surgery \\
\hline & L. plantarum ATCC 10241105 cfu & Daily - topical application for 10 days & $\begin{array}{l}\text { Second and third degree burns } \\
\text { and chronic infected leg ulcers }\end{array}$ \\
\hline & Bifidobacterium bifidum* 3.3*109 cfu & $\begin{array}{l}\text { Oral - } 7 \text { days before and } 5 \text { to } 10 \text { days } \\
\text { after surgery }\end{array}$ & Colorectal Cancer Surgery \\
\hline \multirow{3}{*}{ Pseudomonas aeruginosa } & L. plantarum ATCC 10241105 cfu & Daily - topical application for 10 days & $\begin{array}{l}\text { Second and third degree burns } \\
\text { and chronic infected leg ulcers }\end{array}$ \\
\hline & Bifidobacterium bifidum* 3.3*109 cfu & $\begin{array}{l}\text { Oral - } 7 \text { days before and } 5 \text { to } 10 \text { days } \\
\text { after surgery }\end{array}$ & Colorectal Cancer Surgery \\
\hline & $\begin{array}{c}\text { L. acidophilus LA-5, L. plantarum*, B. Lactis BB-12, } \\
\text { Saccharomyces boulardii*/5.5*109 cfu }\end{array}$ & $\begin{array}{l}\text { Oral - } 1 \text { day prior to operation and } 14 \\
\text { days after surgery }\end{array}$ & Colorectal Cancer surgery \\
\hline \multirow{4}{*}{ Enterococcus faecalis } & $\begin{array}{c}\text { Lactobacillus casei Shirota } \\
\text { Bifidobacterium } \\
\text { Breve Yakult/2*108 cfu }\end{array}$ & Oral for 14 days after surgery & Biliary cancer surgery \\
\hline & L. plantarum ATCC 10241105 cfu & Daily - topical application for 10 days & $\begin{array}{l}\text { Second and third degree burns } \\
\text { and chronic infected leg ulcers }\end{array}$ \\
\hline & $\begin{array}{c}\text { L. acidophilus LA-14, L. plantarum LP-115, } \\
\text { Bifidobacterium lactis BBL-04, L.Casei LC -11, } \\
\text { Lactobacillus rhamnosus LR-32, } \\
\text { Lactobacillus brevis LBr-35/2.75* } 1010 \mathrm{cfu} \\
\end{array}$ & $\begin{array}{l}\text { Oral - at least } 7 \text { days after oral fluid } \\
\text { tolerance post operation }\end{array}$ & Liver Transplantation Surgery \\
\hline & Bifidobacterium bifidum* 3.3*109 cfu & $\begin{array}{l}\text { Oral - } 7 \text { days before and } 5 \text { to } 10 \text { days } \\
\text { after surgery }\end{array}$ & Colorectal Cancer Surgery \\
\hline Acinetobacter baumannii & $\begin{array}{c}\text { L. acidophilus LA-5, L. plantarum, B. Lactis BB-12, } \\
\text { Saccharomyces boulardii/5.5*109 cfu }\end{array}$ & $\begin{array}{l}\text { Oral - } 1 \text { day prior to operation and } 14 \\
\text { days after surgery }\end{array}$ & Colorectal Cancer surgery \\
\hline \multirow[t]{2}{*}{ Escherichia coli } & $\begin{array}{c}\text { L. acidophilus LA-14, L. plantarum LP-115, } \\
\text { Bifidobacterium lactis BBL-04, L. Casei LC -11, } \\
\text { Lactobacillus rhamnosus LR-32, } \\
\text { Lactobacillus brevis LBr-35/2.75* } 1010 \mathrm{cfu}\end{array}$ & $\begin{array}{l}\text { Oral - at least } 7 \text { days after oral fluid } \\
\text { tolerance post operation }\end{array}$ & Liver Transplantation Surgery \\
\hline & Bifidobacterium bifidum* $3.3 * 109 \mathrm{cfu}$ & $\begin{array}{l}\text { Oral - } 7 \text { days before and } 5 \text { to } 10 \text { days } \\
\text { after surgery }\end{array}$ & Colorectal Cancer Surgery \\
\hline Klebsiella pnemoniae & L. plantarum ATCC 10241105 cfu & Daily - topical application for 10 days & $\begin{array}{l}\text { Second and third degree burns } \\
\text { and chronic infected leg ulcers }\end{array}$ \\
\hline Enterobacter spp & $\begin{array}{c}\text { L. acidophilus LA-14, L. plantarum LP-115, } \\
\text { Bifidobacterium lactis BBL-04, L. Casei LC-11, } \\
\text { Lactobacillus rhamnosus LR-32, } \\
\text { Lactobacillus brevis LBr-35/2.75* } 1010 \mathrm{cfu}\end{array}$ & $\begin{array}{l}\text { Oral - at least } 7 \text { days after oral fluid } \\
\text { tolerance post operation }\end{array}$ & Liver Transplantation Surgery \\
\hline
\end{tabular}


Table 2. Pathogens with probiotics along with its benefits

\begin{tabular}{|l|c|l|}
\hline \multicolumn{1}{|c|}{ Pathogen } & \multicolumn{1}{|c|}{ Probiotic } & \multicolumn{1}{c|}{ Potential benefits } \\
\hline $\begin{array}{l}\text { Porphyromonas } \\
\text { gingivalis }\end{array}$ & $\begin{array}{l}\text { Lactobacillus rhamnosus } \\
\text { Lactobacillus paracasei }\end{array}$ & $\begin{array}{l}\text { Strongly binds to saliva } \\
\text { coated surfaces and survives } \\
\text { in the bacterial biofilm }\end{array}$ \\
\hline $\begin{array}{l}\text { Streptococcus } \\
\text { mutans }\end{array}$ & $\begin{array}{l}\text { Lactobacillus rhamnosus GG } \\
\text { Lactobacillus casei }\end{array}$ & $\begin{array}{l}\text { Prevents adherence } \\
\text { of other bacteria and modifies } \\
\text { the protein composition } \\
\text { of salivary pellicle }\end{array}$ \\
\hline $\begin{array}{l}\text { Gram positive } \\
\text { bacteria }\end{array}$ & Weissella cibaria & $\begin{array}{l}\text { Secretes hydrogen peroxide } \\
\text { and bacteriocin that act } \\
\text { against gram positive bacteria }\end{array}$ \\
\hline $\begin{array}{l}\text { Fusobacterium } \\
\text { nucleatum }\end{array}$ & Weissella cibaria & $\begin{array}{l}\text { Effective colonization of oral } \\
\text { cavity through coaggregation } \\
\text { with pathogen and epithelial } \\
\text { cell adherence }\end{array}$ \\
\hline
\end{tabular}

\section{DISCUSSION}

The purpose of this research is to demonstrate the beneficial effects of diverse bacterial strains under varied clinical situations for reducing resistance generated by antibiotic treatment and minimizing drug-related side effects. Although probiotics have been shown to be useful in the majority of research, conventional clinical recommendations for their employment are needed because their protection against systemic infections, harmful metabolic activity, gene transfer and harmful immunomodulation is highly unknown. Studies indicate that lozenges with probiotics are preferred over chewing gums containing standard oral medications. Additional research, however, is needed to determine whether the beneficial benefits of probiotic bacteria are the same when processed or added to food products. Dried probiotics that have been properly prepared and processed will survive the travel through the intestines. In contrast, heat kills active crops. The development of recommendations for the use of probiotics in food, their safety and efficacy assessment, health claims, and probiotic product labeling is a goal shared by all scientists, businesses and health institutes.

\section{CONCLUSION}

The medical community recognizes the potential health benefits of probiotic diets. Still, additional effort is required to solidify the arguments. While the medical community recognizes the potential health benefits of probiotic diets, additional effort is required to solidify the arguments. At this stage, the best we can say is that they will not cause harm and may even be beneficial.

\section{CONFLICT OF INTEREST}

The authors declare none.

\section{ORCID iDs}

Dr Khayati Moudgil (Dhttps://orcid.org/0000-0002-6959-2994

\section{REFERNCES}

1. Hajela N, Ramakrishna B, Nair G, Abraham P, Gopalan S, Ganguly N. Gut microbiome, gut function, and probiotics: Implications for health. Indian Gastroenterol. 2015;34(2):93-107.

2. Probiotic Drinks - How do they work and Top 9 probiotic drinks in India. Stylecraze; 2020. Available from: https://www.stylecraze. com/articles/probiotic-drinks-available-in-india/(cited 2 June 2020)

3. Boindala S, Lewis J. The grand challenge of regulating health foods in India. Indian J Med Res. 2019;150(3):248

4. Raghuwanshi S, Misra S, Sharma R, PS B. Probiotics: Nutritional therapeutic tool. J Prob Health. 2018;06:1.

5. Rodgers S. Incorporation of probiotic cultures in foodservice products: an exploratory study. J Foodservice. 2007;18(3):108-18.

6. Arora M, Baldi A. Comparative study of regulatory framework for probiotics: Current status and future recommendations. Appl Clinl Res Clin Trials Regul Aff. 2017;4(2):140-57.

7. Baldi A. Comparative insight of regulatory guidelines for probiotics in USA, India and Malaysia: A Critical review. Int J Biotech Well Indus. 2013;2(2):51-64.

8. Fijan S, Frauwallner A, Langerholc T, Krebs B, ter Haar (née Younes) J, Heschl A, et al. Efficacy of using probiotics with antagonistic activity against pathogens of wound infections: An integrative review of literature. BioMed Res Int. 2019;2019:1-21.

9. Venosi S, Ceccarelli G, de Angelis M, Laghi L, Bianchi L, Martinelli O, et al. Infected chronic ischemic wound topically treated with a multistrain probiotic formulation: a novel tailored treatment strategy. $J$ Trans Med. 2019;17(1).

10. Roudsari MR, Karimi R, Sohrabvandi S, Mortazavian AM. Health effects of probiotics on the skin. Crit Rev Food Sci Nutr. 2015; 55(9):1219-40.

11. Yang D, Zhao D, Ali Shah S, Wu W, Lai M, Zhang X, et al. The role of the gut microbiota in the pathogenesis of Parkinson's disease. Front Neurol. 2019;10.

12. Scheperjans F, Aho V, Pereira PA, Koskinen K, Paulin L, Pekkonen E, et al. Gut microbiota are related to Parkinson's disease and clinical phenotype. MDS. 2015;30(3):350-8.

13. Magistrelli L, Amoruso A, Mogna L, Graziano T, Cantello R, Pane $\mathrm{M}$, et al. Probiotics may have beneficial effects in Parkinson's disease: In vitro evidence. Front Immunol. 2019;10.

14. Ganci M, Suleyman E, Butt H, Ball M. The role of the brain-gutmicrobiota axis in psychology: The importance of considering gut microbiota in the development, perpetuation, and treatment of psychological disorders. Brain Behav. 2019;9(11):e01408.

15. Jorgenson MR, Descourouez JL, Siodlak M, Tjugum S, Rice JP, Fernandez LA. Efficacy and safety of probiotics and synbiotics in liver transplantation. Pharmacother J Hum Pharmacol Drug Ther. 2018;38(7):758-68.

16. Fijan S, Frauwallner A, Varga L, Langerholc T, Rogelj I, Lorber M, et al. Health professionals' knowledge of probiotics: An international survey. Int J Environ Res Public Health. 2019;16(17):3128.

17. Gupta V, Gupta B. Probiotics and periodontal disease: A current update. J Oral Health Comm Dent. 2010;4(Spl):35-7. 